\title{
Café Mário Em jeito de homenagem
} Christine Zurbach

Título: Café Mário. Autoria e encenação: Pierre-Étienne Heymann. Colaboração à encenação: Rosário Gonzaga. Cenografia e figurinos: Elsa Blin. Sonoplastia: Miguel Reis. Direcção musical: Bruno Cintra. Desenho de luz:António Rebocho. Interpretação: Álvaro Corte Real, Ana Meira, André Salvador, Bruno Cintra, Fábio Moreira, Jorge Baião, José Russo, Maria Marrafa, Rosário Gonzaga, Rui Nuno, Victor Zambujo; Local e data de estreia: Teatro Garcia de Resende, Évora, 19 de Novembro de 2011.

No texto da folha de sala assinado pelo Cendrev, o espectáculo Café Mário, em homenagem a Mário Barradas, é anunciado como um "retrato de uma vida dedicada ao teatro", que "a par desse retrato, desse forma a esse percurso impar que contribuiu de forma decisiva para o aparecimento de novas gerações de homens e mulheres que vieram a dedicar-se profissionalmente ao teatro" (AA.W. 2011: 2). Noutro texto, assinado por Pierre-Étienne Heymann, autor e encenador do espectáculo, o espectador pode ler, no mesmo contexto informativo, que Café Mário é "uma fábula contemporânea", que nos quer falar "dos perigos mortais que ameaçam a arte do teatro - e a arte em geral - na sociedade de hoje." (Heymann, in ibid: 3)

De facto, nos tempos sombrios do final de 2011, a ficção inventada alguns meses antes confrontou-se no momento da sua passagem para a cena, no Outono de 2011, com a dura realidade para o fazer teatral imposta aos profissionais do teatro pelo novo quadro económico de um país decretado bruscamente em falência, a tal ponto que o ritual de um legitimo e merecido acto de homenagem se tornou numa verdadeira arma, artística e discursiva, de exaltação do que constituiu o cerne da militância de Mário Barradas pela arte do teatro, na sua dimensão interventiva, cívica e social, e sobretudo política.

Num contexto em que a companhia do Cendrev é confrontada com a sua própria sobrevivência, muitas das cenas inventadas por Heymann para Café Mário passaram a integrar também o noticiário e os média com a divulgação das decisões tomadas hoje pelos novos governantes. Nesse sentido, uma actualidade adversa ao sonho ou à poesia acabou por enriquecer o tema ideológico central do espectáculo, e reforçou a dimensão histórica da obra artística e teatral construída por Mário Barradas em Évora, de 1975 a 2011.

0 guião do espectáculo segue, numa apropriação oportuna, um modelo formal que recorda as opções do teatro de agitação e propaganda dos anos 1920 que, com fins políticos, recorria à montagem ou à colagem de elementos diversos que favoreciam leituras críticas da realidade transposta para o palco. Aqui, no quadro ideal de uma homenagem levada a cabo pelos actores da companhia profissional do Cendrev que, na posição de representantes actuais (e herdeiros actuantes) de várias gerações de profissionais de teatro que formou, o retrato de Mário Barradas segue uma narrativa que cruza citações de imagens teatrais e componentes do seu discurso programático retiradas do passado, com diálogos originais situados no tempo presente.

0 enredo é resumido por Heymann nestes termos:

\footnotetext{
"No palco de um teatro, um espectro, igual ao de Hamlet, denuncia o assassinio do pai da companhia e, por esse atentado, a extinção progressiva da profissão teatral e da sua acção social. 0 inquérito traz à luz do dia as astúcias das autoridades (a organização "sonsa" do dinheiro), sempre presentes e activas. Os comediantes representam excertos de peças que servem de argumentos, de recordações históricas e de hinos fervorosos. Pouco a pouco organizam a resistência. Com a ajuda dos espectadores, um teatro autêntico pode renascer, no meio do Café Mário" (Ibid.).
}

A peça é composta, como uma obra de padrão clássico, por acções logicamente encadeadas: parte da cena retomada do início de Hamlet aqui aproveitada para dar forma ao homenageado, hoje ausente do nosso mundo como o pai Hamlet, mas presente qual alma penada clamando por uma vingança que obterá no final com a expulsão dos "empaladores" saídos do mundo da saga ubuesca. Na despedida deixa uma recomendação para o futuro:

Agora, adeus! Irmãos actores, nunca se esqueçam que as companhias de teatro devem fazer assentar as suas práticas artísticas em princípios invioláveis, caso contrário serão incapazes de resistir à pressão do pensamento dominante 

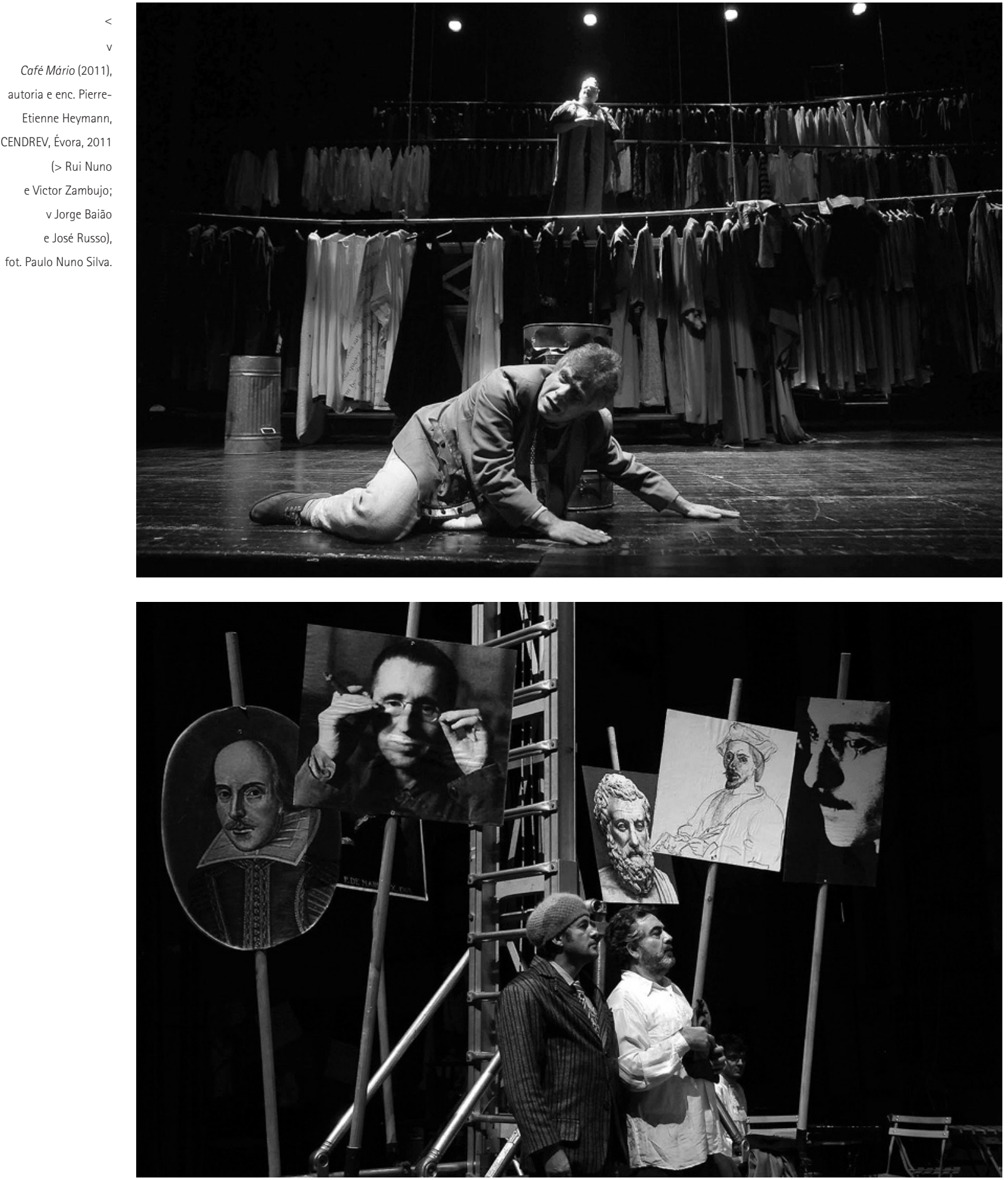

e acabam por deixar erigir a eficácia em estética; caem na armadilha da produtividade a todo o custo, assim fazem o jogo do inimigo que as acabará por destruir" (adaptação de Barradas 1995: 38-45).

Do passado emergem de novo cenas de encenações que constituem o património dos actores do actual Cendrev, todos formados na Escola de Formação Teatral do Centro Cultural de Évora entre 1975 e 1989, o que permite a Pierre-Étienne Heymann introduzir as conhecidas divergências entre quem foi dirigido por um mestre carismático, oscilando entre a quase idolatria da jovem actriz e as reticências de outros. No guião, Heymann incluiu os autores e os textos com maior representatividade canónica no pano de fundo das escolhas de Mário Barradas para o seu repertório pessoal (Zurbach / Ferreira: 2010: 17-28): Marivaux, Ruzante, Gil Vicente e Koltès. Mas o trabalho dos ensaios é sistematicamente interrompido por quem traz um outro projecto para a instituição, ou sobretudo para o uso do edifício e sua função na cidade: um funcionário (é o nome da personagem enviada pelo Secretário de Estado da Cultura), formado em "engenharia cultural", trazido numa liteira por dois criados de casaca setecentista, irrompe pela plateia, alertado pelo rumor acerca do fantasma. 0 diálogo que a sua presença desencadeia transporta o enredo para um outro plano, o 


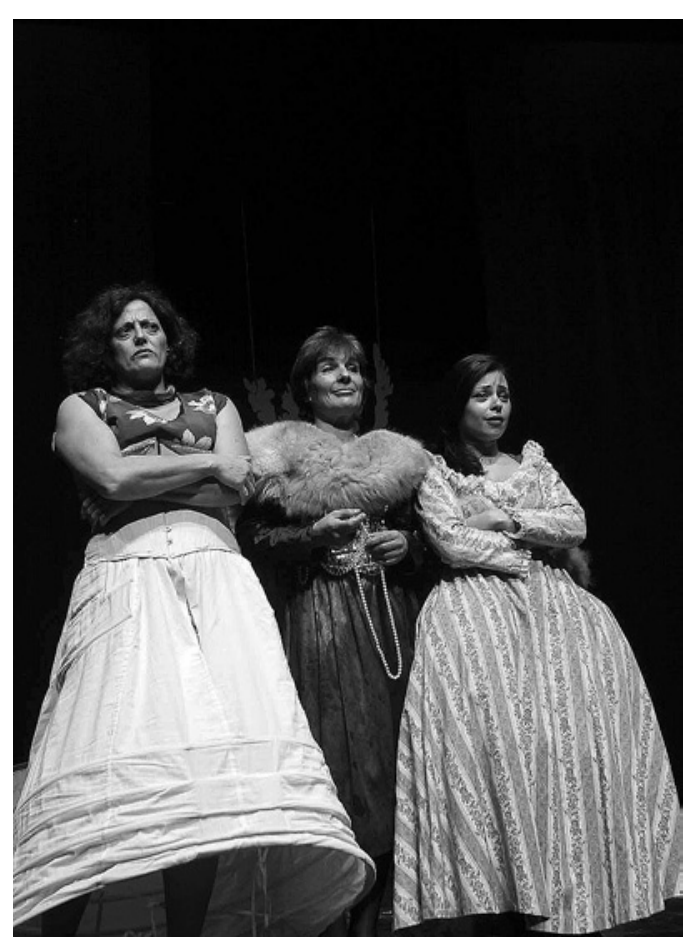

da sociedade bem-comportada, que vê no teatro um factor de desordem de todo o tipo:

Um teatro tem de ser para uma cidade um lugar de divertimento saudável, evidentemente, e além disso acrescentar uma mais-valia económica. Se não preencher essa dupla função e, pior ainda, se desencorajar os investidores, se provocar perturbações da ordem pública, se contaminar os espiritos crédulos, é nosso dever interrogarmonos sobre a pertinência da sua implantação. (Ibid.)

0 velho argumento moral aparece claramente comprometido com o económico, o que, na verdade, não surpreende. Após um encontro com o espectro, furioso, parte para Lisboa, anunciando que, caso o que ele julga ser uma farsa montada contra ele não acabe rapidamente, mandará fechar o teatro.

Em cenas escritas num formato de diálogo filosóficodidáctico, a companhia debate a situação com o filósofo Bertolt de Carvalho, chamado inicialmente para esclarecer o mistério do espectro que assombra o teatro e que está no centro da fábula. Para materializar esta presençaausência, o encenador foi particularmente feliz ao escolher dar ao edifício do Teatro Garcia de Resende, enquanto espaço teatral, um protagonismo cénico multifacetado, usando toda a sua estrutura: da teia desce o recheio do guarda-roupa do Cendrev que, como património não só material, mas também afectivo da companhia, é o primeiro cenário que serve para introduzir o espectro, e permite também pôr em cena a arte, os artefactos e os artifícios do teatro. Do mesmo modo, noutras cenas, a encenação desvendará o velho alçapão que conota o palco à italiana, ou fará chegar ao palco, à vista do espectador, peças de maquinaria em apoio ao jogo dos actores. Para acolher os espectadores, a plateia estende-se, depois do intervalo, para o sub-palco, onde cenas emblemáticas de obras de Ruzante, que são um marco da obra de Mário Barradas como A mosqueta, são interpretadas de acordo com a fórmula dos espectáculos de estrados ou de rua que marcou parte da sua actividade de encenador. No desfecho da peça, o público regressa para o palco onde entretanto foi montada a esplanada do Café Mário. 0 conjunto do belo trabalho cenográfico de Elsa Blin, muito conseguido na escolha da paleta de cores e de texturas do guardaroupa, propõe uma dupla leitura: funciona entre a citação - pela reutilização do espólio existente, que favorece o reconhecimento pelo espectador das obras interpretadas pela companhia numa versão lúdica de um "teatro no teatro", que reproduz gestos caracteristicos do encenador Mário Barradas, agora reproduzidos por outros no seu lugar - e o alerta sobre as escassissimas condições materiais de que pôde dispor no contexto de graves dificuldades financeiras da companhia.

0 desfecho feliz da peça transforma o Café Mário no lugar de uma festa que também envolve alguma emoção para muitos dos espectadores, sobretudo aqueles que também o conheceram como declamador de textos de poetas como Pessoa, Eugénio de Andrade, Manuel da Fonseca, declamados agora pelos actores. E como nas comédias (revolucionárias e optimistas), a fábula do triunfo sobre a adversidade termina com danças e canções, transmitindo como o escreve Heymann, "uma mensagem de esperança e de fé no poder indestrutivel do Teatro" (in AA.W. 2011: 3).

\section{Referências bibliográficas}

AA.W. (2011), Folha de sala do espectáculo Café Mário, Évora, Cendrev, Novembro.

BARRADAS, Mário (1995), "Equivocos", in Adágio, Centro Dramático de Évora, n¹5/16, pp. 38-45

ZURBACH, Christine / FERREIRA, José Alberto (2010), "Mário Barradas: para um retrato do criador teatral", in Sinais de cena, APCT / CET, n. 13, Junho, pp.17-28.
Café Mário (2011), autoria e enc. PierreEtienne Heymann CENDREV, Évora, 2011 (Ana Meira, Rosário Gonzaga e Maria Marrafa), fot. Paulo Nuno Silva. 